\title{
ESTUDIO SOBRE LA LEGALIDAD EN LA DETERMINACIÓN DEL PRECIO Y EL IMPUESTO A LOS COMBUSTIBLES
}

STUDY OF THE LEGALITY IN DETERMINING PRICE AND FUEL TAX

OMAR CONTRERAS BORBÓN ${ }^{1}$

RESUMEN: Este artículo ofrece un panorama del proceso de modificación contemporánea de las normas establecidas en la Ley del Impuesto Especial sobre Producción y Servicios que han avalado tres impuestos IEPS distintos al combustible y dos impuestos al valor agregado; además realiza una aproximación al cálculo de los componentes del precio del combustible tras la liberación de precios de 2017. El autor afirma de ilegal e inconstitucional la manera en que las autoridades administrativas determinan los precios e impuestos de los combustibles, por considerarlo violatorio del principio de doble imposición, contrario al principio de certeza tributaria, al de proporcionalidad, al de legalidad y constitucionalidad. El estudio concluye con una propuesta de solución sencilla que pareciera ser una medida correctiva rápida a la situación y problema fiscal que padecemos en el país, principalmente en la región fronteriza, sobre todo por competir en precio con el sur de Estados Unidos.

Palabras Clave: Derecho Fiscal Mexicano. Derecho Tributario. Combustibles. Gasolinas. Impuesto Especial sobre Producción y Servicios. Impuesto al Valor Agregado. Determinación de precios. Equidad. Constitucionalidad. Doble imposición. Certeza tributaria. Proporcionalidad. Legalidad. Subsidio.

ABStRACT: This article offers a panorama of the process of contemporary modification of the norms established in the Law of the Special

\footnotetext{
${ }^{1}$ Doctorante del Instituto de Investigaciones Jurídicas de la UNAM. Licenciado en Política y Gestión Social, Licenciado en Derecho, Maestro en Derecho Fiscal y especialidad en Evaluación de Impacto Legislativo. Profesor de Derecho Fiscal, Medios de Defensa Fiscal, Derecho Aduanero e Impuestos al Comercio Exterior. Autor de artículos especializados y colaborador en Radio Fórmula y MVS.<omar.borbon@gmail.com>
} 
Tax on Production and Services that have endorsed three IEPS taxes other than fuel and two taxes on added value; It also provides an approximation to the calculation of fuel price components after the price release of 2017. The author states that the way in which the administrative authorities determine the prices and taxes of fuels is illegal and unconstitutional, considering it to be in violation of the principle of double taxation, contrary to the principle of tax certainty, to proportionality, to legality and constitutionality. The study concludes with a simple solution proposal that seems to be a quick corrective measure to the situation and fiscal problem that we suffer in the country, mainly in the border region, mainly because of competing in price with the South of the United States.

Keywords: Mexican Tax Law. Tax Law. Fuels Gasolines Special tax on production and services. Value Added Tax. Determination of prices. Equity. Constitutionality Double taxation. Tax certainty. Proportionality Legality. Subsidy.

SUMARIO: I. Introducción; II. La falsa idea del subsidio; III. ¿Qué pagamos con el combustible?; IV. La legalidad en la determinación del precio y los impuestos a los combustibles; V. ¿Qué resta por hacer?; VI. Fuentes.

\section{I N T RO D U C C I Ó N}

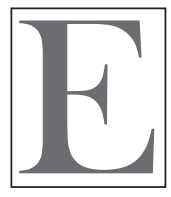

presente trabajo ofrece un panorama analítico sobre la legalidad en la determinación del precio y el impuesto a los combustibles en México. He tenido la oportunidad en artículos de opinión de revistas especializadas en temas fiscales como Asesores en Soluciones, AS y TLC Magazine, así como en distintos medios de comunicación, de expresar algunas ideas sobre por qué considero ilegal e inconstitucional la manera en que las autoridades administrativas determinan los precios y los tributos de los combustibles. Lo mismo he sostenido en medios impresos en los que colaboro o en donde me han dado la 
oportunidad de expresar mi opinión; al presentar este trabajo, he tenido la oportunidad de confrontar esa hipótesis y sostener como cierta la afirmación que en ella hago.

En primer lugar, el trabajo esboza los motivos por los cuales creo que jamás ha existido un subsidio a los combustibles, sino simplemente un estímulo fiscal que disminuía la cantidad de impuestos que debían pagarse por el consumo del combustible y por ende, disminuía el precio sobre todo en región o franja fronteriza. Seguidamente, dedico unas líneas al estudio de las normas que determinan el precio del combustible, tratando de analizar historicamente las normas establecidas en la Ley del Impuesto Especial sobre Producción y Servicios que han avalado tres impuestos IEPS distintos al combustible y dos impuestos al valor agregado; en este apartado en específico se realiza el cálculo de los componentes del combustible. En el tercer y último apartado sostengo de ilegal e inconstitucional la manera en que las autoridades administrativas determinan los precios e impuestos de los combustibles, por considerarlo violatorio del principio de doble imposición, contrario al principio de certeza tributaria, al de proporcionalidad, al de legalidad y constitucionalidad. Es ilegal que sea la Comisión Reguladora de Energía con la opinión de la Comisión Federal de Competencia Económica, quien determine los precios de los combustibles, es una facultad establecida en el artículo Décimo Segundo Transitorio de la Ley de Ingresos de la Federación para 2017; pero es facultad exclusiva del Congreso de la Unión según el artículo 73 fracción XXIX de la Constitución Política de los Estados Unidos Mexicanos; por lo tanto es violatorio del principio de legalidad tributaria y a todas luces una medida inconstitucional.

Concluyo con una propuesta de solución sencilla que pareciera ser una medida correctiva rápida a la situación y problema fiscal que pade- 
cemos en el país, principalemente en la región fronteriza, sobre todo por competir en precio con el sur de Estados Unidos.

\section{LA FALSA IDEA DEL SUBSIDIO}

Los mexicanos conocemos con siglas lo que un subsidio significa: Conasupo, Solidaridad, Seguro Popular, Liconsa, Diconsa, Procampo, Oportunidades, Prospera y una larga lista de programas diseñados para entregar apoyos, estimular el consumo o la producción nacional, con los que el gobernante en turno imprime su sello a su tiempo político para ser recordado como benefactor social.

Se subsidia un producto cuando se promueve su venta al público a un precio menor del costo de producción, ocurrió en el pasado con en el maíz para la tortilla y ocurre actualmente con la leche Liconsa, pero ese famoso subsidio no ha ocurrido con el combustible que enajena Pemex, al menos no desde 2015 .

El Diccionario de Derecho en línea específica lo siguiente respecto a su significado:

Con origen en el latín subsidium, el concepto de subsidio permite identificar a una asistencia pública basada en una ayuda o beneficio de tipo económico. Se trata de un sistema enfocado a estimular el consumo o la producción, o de una ayuda que se otorga por un tiempo determinado $[\ldots]$

Podría definirse a esta noción como la diferencia que se advierte al comparar el valor real de un producto o prestación y el valor que paga el consumidor para acceder a dicho producto o servicio. En estas circunstancias, el gobierno reparte subsidios a las compañías para evitar que los precios o las tarifas se incrementen. $[. . .]^{2}$

\footnotetext{
219 de mayo de 2017, http://definicion.de/subsidio/
} 
Por su parte, el Glosario de Términos de Derecho Fiscal de Víctor Manuel Alfaro Jiménez define Subsidio como un apoyo de carácter económico que el Estado concede a las actividades productivas de los particulares con fines de fomento durante períodos determinados y que se considera como la especie del género denominado subvención.

En cuanto a la definición de estímulo fiscal en las leyes fiscales mexicanas no existe definición alguna; sin embargo, el Código Fiscal de la Federación, la Ley de Ingresos de la Federación y la Ley del Impuesto Sobre la Renta refieren la existencia de esta figura jurídica y otorgan reglas para su aplicación, otorgando a través de ellos disminuciones a la carga fiscal, simplificación administrativa y beneficios con base en acreditamientos, reducciones, deducciones, sin embargo nunca la conceptualizan, lo cual, de acuerdo a lo que señala la Contadora Pública y Maestro en Impuestos María Elena Domínguez Ortiz, mantiene vigente y en permanente estado la confusión. Lo anterior es expuesto ampliamente en la revista especializada en Derecho Fiscal, Asesores en Soluciones, de marzo de 2014.

Existe una interpretación jurisdiccional que establece que el estímulo fiscal es un subsidio económico concedido por ley al sujeto pasivo de un impuesto, con el objeto de obtener de él ciertos fines parafiscales, que no representan un desvanecimiento de la obligación tributaria sino que ésta es asumida por el Estado. ${ }^{3}$

De conformidad con el Glosario del Servicio de Administración Tributaria, Estímulo Fiscal lo define de la siguiente manera:

Son apoyos gubernamentales que se destinan a promover el desarrollo de actividades y regiones específicas, a través de mecanismos tales como

3 Tesis: Cuarto Tribunal Colegiado de Circuito. Jurisprudencia V., 4o J/1. IUS 2008. Registro 179585. Publicada en el Semanario Judicial de la Federación y su Gaceta. Novena Época. Tomo XXI, enero 2005, p. 1566. 
disminución de tasas impositivas, exención de impuestos determinados, aumento temporal de tasas de depreciación de activos, etc. [...]

Tienen por objetivo:

1. Fomentar artificialmente el consumo, la producción o adquisición de un bien o servicio.

2. Son los mecanismos contrarios a los impuestos. Los estímulos tienen su origen en la intención de los Estados de alcanzar metas sociales, o bien para favorecer (por distintas razones) a determinadas personas, actividades o zonas de un país.

3. Cuando son otorgados desde el Estado a las empresas privadas, pueden tener el fin de evitar que posibles aumentos de tarifas lleguen a los consumidores finales de los productos o servicios que ellas proveen, y así proteger la economía regional. ${ }^{4}$

Dado que los estímulos y los subsidios tienen un fin totalmente opuesto a los impuestos, el término estímulo fiscal, provoca todavía más confusiones ya que lo fiscal es recaudatorio y no un medio de entrega de recursos o de beneficios adicionales.

Por lo anterior, en tanto subsidio refiere a reparto de recursos públicos para incentivar la producción o el consumo de determinados bienes y servicios; el estímulo fiscal logra exactamente el mismo propósito pero eliminando total o parcialmente los impuestos que deben pagarse por el consumo de dichos productos o servicios.

Del estudio y la interpretación del significado de cada una de los conceptos, se advierte que lo que existió en el caso del combustible hasta el 31 de diciembre de 2016 fue un estímulo fiscal, no un subsidio, que afectaba exclusivamente el Impuesto Especial sobre Producción y Servicios (IEPS) disminuyendo su tasa, mayormente acentuado en el caso de la frontera norte del país, a fin de homologar los precios con los de las

\footnotetext{
${ }^{4}$ Mayo de 2017, http://sat.gob.mx/informacion_fiscal/glosario/Paginas/glosario_e.aspx
} 
regiones fronterizas del Sur de Estados Unidos. En ningún momento el costo de producción fue mayor al precio de venta y por tanto no pudo existir subsidio.

Falsamente se ha mencionado que el costo de combustible durante 2016 generó un subsidio de 217 mil millones de pesos. Lo que ocurrió es que el Gobierno dejó de ingresar esos recursos al mantener el precio del combustible en México más bajo al promedio internacional: no puede ser de otra manera. Los mexicanos somos dueños del 6petróleo con el que se producen las gasolinas, además de refinar el 40 por ciento de ellas en las 6 plantas en territorio nacional y otro porcentaje en la refinería de Deer Park en Texas, donde Pemex está asociada con Shell al 50 por ciento. Siendo dueño de la materia prima con la que se produce y produces la mitad de lo que consumes: ¿por qué tendrías que venderla más cara?

\section{III. ¿QUÉ PAGAMOS CON EL COMBUSTIBLE?}

Antes de los famosos gasolinazos del período de Felipe Calderón, existía ya en la Ley del IEPS un impuesto para los combustibles. Era un impuesto que hacía las veces de regulador del precio de la gasolina y trataba de compensar los precios internacionales en favor de los mexicanos, su fórmula de cálculo era extremadamente compleja: representaba un porcentaje que se ajustaba según el precio internacional del petróleo subiera o bajara. Si el precio del petróleo estaba bajo, entonces el IEPS de gasolinas y diésel se incrementaba, el gobierno recaudaba así impuestos adicionales sin que la ciudadanía los sintiera. Esa recaudación extra llegó a sumar más del 1 por ciento de la producción nacional anual.

Cuando el costo del petróleo en el mercado internacional se cotizaba alto, entonces el IEPS de gasolinas y diésel se volvía negativo, es decir 
que en vez de cobrar, subsidiaba. Ese estímulo fiscal llegó a representar en algún momento anualmente casi el 0.7 por ciento de la producción nacional.

Ese impuesto tenía su base legal en el anterior artículo 2 A de la Ley del IEPS. Este IEPS se fue ajustando con el transcurso del tiempo e implicó finalmente un cálculo del costo de la Terminal de Almacenamiento y Reparto (TAR) de PEMEX que consideró también los precios de referencia en el Golfo, costos de refinación, las mermas, los costos de importación, la cotización del dólar, las comisiones a los expendedores de combustible, tipo de cambio peso-dólar, forma en la que se calculaba entonces el precio de la gasolina y en la que se tasaba por ende el impuesto especial del artículo 2 A fracción I de la Ley Especial sobre Producción y Servicios.

Artículo 2o.-A. Las personas que enajenen gasolina o diesel en territorio nacional estarán sujetas a las tasas y cuotas siguientes:

1. La tasa aplicable en cada mes para la enajenación de gasolinas o diesel será la que resulte para cada Terminal de Almacenamiento y Reparto de Petróleos Mexicanos conforme a lo siguiente:

a) Precio productor: Se determinará para las gasolinas y el diesel de uso automotriz, industrial de bajo azufre y en vehículos marinos, adicionando al precio de referencia ajustado por calidad, cuando proceda, que se determine para el combustible de que se trate de acuerdo con el inciso f) de esta fracción, así como el costo de manejo y el costo neto de transporte a la Terminal de Almacenamiento y Reparto de que se trate en el periodo señalado en el inciso f) de esta fracción, sin incluir el impuesto al valor agregado. b) Costo de distribución y comercialización: Para los combustibles señalados en el inciso a) y para el periodo señalado en el inciso f) de esta fracción, se determinará para cada Terminal de Almacenamiento y Reparto, adicionando al margen comercial que haya 
fijado Petróleos Mexicanos para los expendios autorizados por el combustible de que se trate, en su caso, los costos netos de transporte del combustible de la Terminal de Almacenamiento y Reparto que corresponda al establecimiento del expendedor, ya sea realizado por Petróleos Mexicanos o por un tercero con el que el organismo tenga celebrado un contrato de Venta de Primera Mano y que cumpla la realización del transporte en los términos de la normatividad correspondiente. El monto obtenido se dividirá entre el volumen total facturado del combustible de que se trate.

Únicamente para las gasolinas, se considerará dentro del costo unitario de distribución y comercialización, el monto por concepto de mermas, que se determinará multiplicando el factor de 0.003375 por el valor total de las enajenaciones de gasolinas a las estaciones de servicio sin considerar lo señalado en la fracción II de este artículo, así como las señaladas en el inciso H) de la fracción I, del artículo 2o. de esta Ley, ni tampoco el impuesto al valor agregado, dividido por el volumen total del combustible en el periodo señalado en el inciso f) de esta fracción.

c) Precio neto de venta en la Terminal de Almacenamiento y Reparto: Se determinará, cuando se lleve a cabo la enajenación, descontando al precio de venta al público del combustible de que se trate, vigente en la zona geográfica correspondiente en el periodo citado, en el inciso f) de esta fracción, los montos de las cuotas señaladas en la fracción II de este artículo, multiplicado por el factor, redondeado a cuatro decimales, que resulte de la siguiente fórmula:

$$
\begin{array}{|c|}
\hline 1 \\
\hline 1+T \\
\hline
\end{array}
$$

Donde $\mathrm{T}$ corresponde a la tasa del impuesto al valor agregado, expresado en decimales de conformidad con lo señalado en la Ley del Impuesto al Valor Agregado. 
$\mathrm{Al}$ monto que resulte se le restarán las cuotas señaladas en el inciso H) de la fracción I del artículo 2o. de esta Ley, de acuerdo al combustible de que se trate.

d) El monto que resulte conforme al inciso c) anterior, se disminuirá con las cantidades obtenidas conforme a los incisos a) y b) de esta fracción.

e) La cantidad determinada conforme al inciso d) anterior, se dividirá entre el monto que se obtuvo conforme al inciso a) de esta fracción y el resultado se multiplicará por 100. El porcentaje que se obtenga será la tasa aplicable al combustible de que se trate que enajene la Terminal de Almacenamiento y Reparto correspondiente, durante el mes por el que se calcula la tasa.

f) El precio de referencia para cada uno de los combustibles a que se refiere el inciso a) de esta fracción, será el promedio de las cotizaciones disponibles del día 21 del segundo mes anterior al día 20 del mes inmediato anterior a aquél por el que se calcula la tasa, convertidas a pesos con el promedio del tipo de cambio de venta del dólar de los Estados Unidos de América que publica el Banco de México en el Diario Oficial de la Federación, para el mismo periodo, como sigue:

1. Gasolinas: el promedio del precio spot de la gasolina de calidad equivalente, vigente en la Costa del Golfo de los Estados Unidos de América, a la gasolina que se enajene en territorio nacional.

2. Diesel para uso automotriz y diesel para uso industrial de bajo azufre: el promedio del precio spot (fuel oil) del diesel de calidad equivalente, vigente en la Costa del Golfo de los Estados Unidos de América, al diesel que se enajene en territorio nacional.

3. Diesel para uso en vehículos marinos: el promedio del precio spot (fuel oil) del diesel de calidad equivalente, vigente en Houston, Texas, de los Estados Unidos de América, al diesel 
que se enajene en territorio nacional en la Costa del Golfo de México; y el promedio del precio spot (fuel oil) del diesel de calidad equivalente, vigente en Los Ángeles, California, de los Estados Unidos de América, al diesel que se enajene en territorio nacional en la Costa del Pacífico.

Para la determinación de los montos señalados en los incisos a), b) y c), los volúmenes se expresarán en metros cúbicos.

La Secretaría de Hacienda y Crédito Público, mediante reglas de carácter general basadas en criterios de eficiencia económica y saneamiento financiero, dará a conocer los elementos para determinar los precios de referencia, los ajustes por calidad, los costos netos de transporte, el margen comercial y el costo de manejo a los expendios autorizados a que se refiere esta fracción.

La Secretaría de Hacienda y Crédito Público, requerirá a Petróleos Mexicanos la información necesaria para realizar mensualmente las operaciones aritméticas para calcular las tasas aplicables en el mes de que se trate para cada combustible y en cada agencia de ventas, Terminal de Almacenamiento y Reparto de Petróleos Mexicanos y las publicará en el Diario Oficial de la Federación, a más tardar el último día del mes anterior, al mes en que aplicarán las tasas.

Se continuarán aplicando las tasas publicadas en el mes inmediato anterior hasta en tanto se haga la publicación a que se refiere el párrafo anterior.

Como vemos, la determinación en el costo del precio del combustible, y por consiguiente de sus impuestos, resultaba más en una decisión de tipo político que razones técnico-económicas; en tanto la mayor parte de este artículo mencionaba la manera en que se cotizaba, jamás supimos a ciencia cierta las cantidades que servían de base para determinarlo. No obstante la estructura jurídica y la complicación técnica que implicaba el 
estudio y el análisis de la fracción I del artículo $2^{\circ}$, el Gobierno Federal siempre tenía alternativa para la determinación de los precios, la solución se establecía en el penúltimo párrafo:

La Secretaría de Hacienda y Crédito Público, mediante reglas de carácter general basadas en criterios de eficiencia económica y saneamiento financiero, dará a conocer los elementos para determinar los precios de referencia, los ajustes por calidad, los costos netos de transporte, el margen comercial y el costo de manejo a los expendios autorizados a que se refiere esta fracción.

La Terminal de Almacenamiento y Reparto implicaba entonces calcular el costo del combustible en las más de 80 terminales terrestres y marítimas de almacenamiento y despacho ubicadas estratégicamente a lo largo del territorio nacional, calculando la cadena de suministro entre los centros productores, puntos de importación y los canales de comercialización de productos petrolíferos, atendiendo las necesidades de los franquiciatarios y del mercado para facilitar las actividades diarias de los consumidores finales.

La capacidad de almacenamiento nominal de estas famosas terminales es superior a los 30 millones de barriles y 41 muelles con servicios portuarios para entrega y recepción de operaciones marítimas, así como 5.5 millones de barriles diarios de capacidad de entrega por diferentes medios de transporte.

Con la famosa reforma de Felipe Calderón que entró en vigor en 2008, en donde se creó el Impuesto Empresarial a Tasa Única, se reformó la Ley del IEPS para aplicar cuotas estatales; se creó una sobre tasa al IEPS que se fijó en una nueva fracción II del artículo 2 A, y que aplicaron cuotas a la gasolina Magna de 36 centavos, a la Premium de 43.92 centavos y al Diésel de 29.88 centavos por litro. 
Estos recursos de impuestos federales son 100 por ciento participables a las entidades federativas, son netamente para sufragar el gasto público de los gobiernos de los estados y se suponía que estaría vigente solamente hasta 2012, como sabemos está vigente hasta nuestros días.

A diferencia del IEPS contenido en el artículo 2 A, fracción I, éste no se computa para el cálculo del impuesto al valor agregado.

Artículo 20.-A ...

I. ...

II. Sin perjuicio de lo previsto en la fracción anterior, y en lo dispuesto en el artículo 2o., fracción I, inciso H), se aplicarán las cuotas siguientes:

a) Gasolina Magna 36 centavos por litro.

b) Gasolina Premium UBA 43.92 centavos por litro.

c) Diesel 29.88 centavos por litro.

Los recursos que se recauden en términos de esta fracción, se destinarán a las entidades federativas, municipios y demarcaciones territoriales, conforme a lo establecido en la Ley de Coordinación Fiscal.

Un tercer impuesto IEPS fue el creado en la reforma del 2015, que creó un impuesto especial a combustibles fósiles, supuestamente con fines ecológicos, sustentado en el artículo 2, fracción I, inciso H de la Ley del IEPS que estableció una cuota de 12.59 centavos por litro para diésel y 10.38 centavos por litro para gasolinas. Este es el tercer impuesto IEPS. Artículo 2o.- Al valor de los actos o actividades que a continuación se señalan, se aplicarán las tasas y cuotas siguientes:

I. En la enajenación o, en su caso, en la importación de los siguientes bienes: 


\begin{tabular}{|c|c|c|}
\hline H) Combustibles Fósiles & Cuota & Unidad de medida \\
\hline 1. a $2 . .$. & & \\
\hline 3. Gasolinas y gasavión & 10.38 & centavos por litro. \\
\hline 4.a $10 \ldots$ & & \\
\hline
\end{tabular}

Como vemos hasta aquí, en México existían hasta el 31 de diciembre de 2016, dos impuestos que gravaban el consumo de combustibles: el Impuesto Especial Sobre Producción y Servicios por enajenación de gasolinas y diésel y el Impuesto al Valor Agregado. En el caso del IEPS sobre combustibles se establecía en tres diferentes espacios en la Ley, el primero establecido en el Artículo 2A fracción I, tasa que fluctúa mensualmente de acuerdo con la brecha existente entre el precio del productor y el precio de venta al público o, en específico, el precio de venta antes de llegar a la estación de servicio, excluyendo el costo del flete, la ganancia de los franquiciatarios y los impuestos. La segunda, referida en el Artículo 2A fracción II, corresponde a una tarifa por litro enajenado, que actualmente es de 36 centavos para la gasolina Magna, 43.92 para la gasolina Premium y 29.88 para el Diesel. El tercer impuesto IEPS es el del Artículo 2, fracción I, inciso $\mathrm{H}$ de 10.38 centavos por litro a gasolinas.

Por otro lado, el Impuesto al Valor Agregado es otro gravamen que recae sobre la venta de dichos petrolíferos. Las tasas vigentes son el $16 \%$ para gravar el consumo al interior del país, es importante notar que éste es un impuesto sobre un impuesto, por lo que la política sobre el IEPS petrolero altera también la recaudación del IVA petrolero.

La gran apuesta en 2015 al flexibilizar los precios de las gasolinas a precios internacionales, fue establecer el IEPS del artículo 2 A fracción I a cuotas fijas, para que en vez de que se calcule como porcentaje, ahora sea una cifra fija, o cuota. 
Pero la base que se tomó para determinar la cuota fue la de los precios internacionales del petróleo del 2012, cuando el precio del barril del petróleo estaba en 120 dólares; así tenemos que el IEPS quedó en 4.7941 pesos por litro de Magna, 4.2178 pesos por litro de Premium, y 5.1802 pesos por litro de diésel. A este IEPS se le aplica adicionalmente Impuesto al Valor Agregado, lo que viola el principio de doble tributación que establece la ilegalidad de tasar varios impuestos sobre la misma base. Como hemos visto, en el caso de la gasolina los mexicanos pagamos 3 impuestos especiales y el impuesto al Valor Agregado.

Como sabemos la gasolina Magna incrementó su precio en 2017 en un 14.2 por ciento al pasar de 13.98 a 15.99 pesos por litro, la Premium en 20.1 por ciento al pasar de 14.81 a 17.70 pesos el litro; y, el Diésel en un 16.5 por ciento al pasar de 14.63 a 17.05 pesos por litro.

\section{ACUERDO $99 / 2016$}

ACUERDO POR EL QUE SE ACTUALIZAN LAS CUOTAS QUE SE ESPECIFICAN EN MATERIA DEL IMPUESTO ESPECIAL SOBRE PRODUCCIÓN Y SERVICIOS.

ACUERDO.

Artículo primero. El factor de actualización aplicable para el año de 2017 a las cuotas a las que se refieren los artículos 2o., fracción I, incisos D) y H), y 2o.-A, fracciones I, II y III de la Ley del Impuesto Especial sobre Producción y Servicios, es de 1.0330, resultado de dividir el Índice Nacional de Precios al Consumidor del mes de noviembre de 2016, que fue de 121.953 puntos, y el mencionado índice correspondiente al mes de noviembre de 2015, que fue de 118.051 puntos, procedimiento establecido conforme a lo dispuesto por el artículo 17-A del Código Fiscal de la Federación. 
Artículo segundo. Conforme al factor de actualización mencionado en el artículo Primero de este Acuerdo, las cuotas aplicables a los combustibles automotrices a que se refiere el artículo 2o., fracción I, inciso D) de la Ley del Impuesto Especial sobre Producción y Servicios, que estarán vigentes a partir del 1 de enero de 2017, son las siguientes:

\begin{tabular}{|l|l|l|}
\hline Combustibles fósiles & Cuota & Unidad de medida. \\
\hline Gasolina menor a 92 octanos & 4.30 & pesos por litro. \\
\hline Gasolina mayor o igual a 92 octanos & 3.64 & pesos por litro. \\
\hline Diésel & 4.73 & pesos por litro. \\
\hline Combustibles no fósiles & 3.64 & pesos por litro. \\
\hline
\end{tabular}

Artículo Tercero. Conforme al factor de actualización mencionado en el artículo Primero de este Acuerdo, las cuotas aplicables a los combustibles fósiles a que se refiere el artículo 2o., fracción I, inciso H) de la Ley del Impuesto Especial sobre Producción y Servicios, que estarán vigentes a partir del 1 de enero de 2017, son las siguientes:

\begin{tabular}{|l|c|l|}
\hline \multicolumn{1}{|c|}{ Combustibles Fósiles } & Cuota & \multicolumn{1}{c|}{ Unidad de medida } \\
\hline 1. Propano & 6.50 & centavos por litro. \\
\hline 2. Butano & 8.42 & centavos por litro. \\
\hline 3. Gasolinas y gasavión & 11.41 & centavos por litro. \\
\hline 4.Turbosina y otros kerosenos & 13.64 & centavos por litro. \\
\hline 5. Diesel & 13.84 & centavos por litro. \\
\hline 6. Combustóleo & 14.78 & centavos por litro. \\
\hline 7. Coque de petróleo & 17.15 & pesos por tonelada. \\
\hline 8. Coque de carbón & 40.21 & pesos por tonelada. \\
\hline 9. Carbón mineral & 30.28 & pesos por tonelada. \\
\hline 10. Otros combustibles fósiles & 43.77 & $\begin{array}{l}\text { pesos por tonelada de carbono } \\
\text { que contenga el combustible. }\end{array}$ \\
\hline
\end{tabular}

Artículo Cuarto. Conforme al factor de actualización mencionado en el artículo Primero de este Acuerdo, las cuotas aplicables a las gasolinas y el diésel previstas en el artículo 20.-A, fracciones I, II y III de la Ley del 
Impuesto Especial sobre Producción y Servicios, que estarán vigentes a partir del 1 de enero de 2017, son las siguientes:

\begin{tabular}{|l|l|l|}
\hline Combustibles & Cuota & Unidad de medida \\
\hline Gasolina menor a 92 octanos & 38.00 & centavos por litro. \\
\hline Gasolina mayor o igual a 92 octanos & 46.37 & centavos por litro. \\
\hline Diésel & 31.54 & centavos por litro. \\
\hline
\end{tabular}

En el caso de la gasolina Magna el IEPS total 4.7941pesos, más IVA en dos de ellos por 0.7063 pesos. Adicionalmente se carga IVA en el precio del producto que es de 9.043 pesos por litro de gasolina Magna y el correspondiente IVA de 1.45 pesos por litro. Así tenemos que en total se pagan 4.7941 pesos de IEPS y 2.1563 pesos de IVA. El precio del producto es de 9.043 pesos, tomando en consideración todos los costos.

¿Disminuyó el IEPS en 2017?: ¡NO!, los impuestos se mantuvieron constantes en valores nominales, pero se incrementó el costo de producción para homologarlo a precios internacionales. Así, mientras en julio de 2016 el costo de producción representaba un 55.7 por ciento del precio del litro de Magna, el IEPS el 30.9 por ciento y el IVA el 13.4 por ciento; para enero de 2017 el porcentaje de la producción se estima en 56.55 por ciento del precio del litro Magna, el IEPS el 29.98 por ciento y el IVA el 13.48 por ciento.

Aunque el componente porcentual del costo de la gasolina sea distinto, el valor nominal de los impuestos no bajó: la Magna seguirá pagando más de 4 pesos por IEPS y más de 2 pesos en IVA.

\section{LA LEgALIDAd EN LA DETERMINACIÓN DEL PRECIO Y LOS IMPUESTOS A LOS COMBUSTIBLES.}

La decisión del Gobierno Federal de eliminar el estímulo fiscal a los combustibles y liberar sus precios es una medida netamente recaudatoria, así se estableció incluso en los Criterios Generales de Política Eco- 
nómica y en la Exposición de Motivos de la Ley de Ingresos de la Federación (LIF) del 2017, que establece que el gobierno federal tendrá una recaudación total de 284 mil 432 millones de pesos por concepto del impuesto especial, esto es 36 por ciento mayor a lo que se estimó en la LIF del 2016, lo que representa 75 mil 46 millones de pesos adicionales.

Pero esa cifra podría superarse con facilidad, así ha venido ocurriendo todos los años, por ejemplo en 2016 se esperaba una recaudación total por 209 mil 386 millones de pesos por IEPS a gasolina y diésel, y para el cierre de octubre de 2016, la recaudación ya sumaba 239 mil 999 millones de pesos.

Los Criterios Generales de Política Económica para 2017, establecían en su página 11 lo siguiente:

Para continuar con la implementación de la Reforma Energética, el Paquete Económico 2017 propone adelantar a partir de enero de 2017 la liberalización del precio de las gasolinas y el diésel, de manera gradual y ordenada. Para ello, se propone la Comisión Reguladora de Energía (CRE), órgano regulador del sector, junto con la Comisión Federal de Competencia Económica (COFECE) determinen el ritmo de la liberalización de los precios para las distintas regiones del país. Con ello, la propuesta busca garantizar una apertura ordenada, basada en el análisis de dos instituciones con profunda capacidad técnica. Esta propuesta dará un impulso definitivo a la apertura del mercado de suministro de combustibles, con lo que se detonará una mayor inversión productiva. Con la propuesta, México se pondría a la par de la mayoría de los países miembros de la OCDE y de América Latina.

a) Principios tributarios en México

La bibliografía principal de este apartado son dos textos. El primero titulado "Los principios de Derecho Tributario" de Alex R. Zambrano 
Torres; y, el segundo intitulado "El Derecho Constitucional Tributario" del Dr. Juan Manuel Ortega Maldonado, profesor investigador de Derecho Fiscal en el la Facultad de Derecho de la Universidad Autónoma de Morelos.

Esta última obra, sobre la que habremos de escudriñar, señala que la materia fiscal guarda una estrecha relación con la Constitución, de ahí que uno de los principios fundamentales del derecho fiscal sea precisamente el llamado principio de constitucionalidad.

Por otro lado, de acuerdo a Alex Zambrano los Principios del Derecho Tributario existen por ser límites a la potestad tributaria, es decir existen como control del poder del Estado para crear, modificar y extinguir tributos. Zambrano incluso afirma que los principios tributarios son el límite del Poder Tributario del Estado, a fin de que no se vulnere los derechos fundamentales de la persona, ni se colisione con otros sectores y potestades con las cuales se debe coexistir.

El Derecho Fiscal es una de las ramas del Derecho Administrativo y como tal pertenece al Derecho Público. No puede entenderse el Derecho Público sin emanar de la norma que rige el pacto federal, ésta es la Constitución Política de los Estados Unidos Mexicanos; por lo tanto, el Derecho Fiscal tiene base constitucional. De ahí que los principios tributarios que menciona Zambrano sean en una cantidad mayor a los que por norma constitucional pertenezcan al ámbito de aplicación estrictamente constitucional, aquellos son de tipo doctrinario, pertenecientes al conjunto de opiniones emitidas por juristas, mientras que los segundos, los constitucionales, se encuentran plasmados en la Constitución Política de los Estados Unidos Mexicanos, en específico en el artículo 31 fracción IV, a esta norma específica se encuentra acotada la potestad tributaria del Estado. 
Los principios tributarios constitucionales contenidos en la fracción IV del artículo 31 de la Carta Magna son los que se desprenden del contenido literal de dicha fracción, a mayor abundamiento, es el que sigue: "Artículo 31. Son obligaciones de los mexicanos: (I. a III. ...) IV.- Contribuir para los gastos públicos, así de la Federación, como del Distrito Federal o del Estado y Municipio en que residan, de la manera proporcional y equitativa que dispongan las leyes."

De lo anterior, por tanto, se desprenden, de acuerdo al orden de aparición, los siguientes principios constitucionales tributarios: el de obligatoriedad, el de destino al gasto público, el de proporcionalidad y equidad, y el de legalidad. A éstos Ortega Maldonado agrega los de no confiscatoriedad, no exención y mínimo vital exento.

A estos se suman los principios tributarios de carácter doctrinario, incluso ya presentes en jurisprudencias de nuestro máximo Tribunal, como son el de justicia, uniformidad, respeto de los derechos fundamentales, certeza, economía en la recaudación, capacidad contributiva, estabilidad económica, y eficacia en la asignación de recursos, todos ellos señalados por el texto de Zambrano Torres.

Como señalamos al inicio del presente Ensayo, abundaremos sobre los principios tributarios constitucionales; vale la pena entonces señalar que ni Zambrano Torres ni Ortega Maldonado realizan un análisis exhaustivo de dichos principios, el primero preocupado por abarcarlos todos, o casi todos, y explicarlos de manera sucinta, el segundo, por preocuparse en abundar sobre las facultades de recaudación y los principios tributarios que rigen la vida local a diferencia de la federal.

El principio de legalidad es un principio fundamental del Derecho Tributario. Generalmente es reconocido por los ordenamientos supremos como la Constitución Política de los Estados Unidos Mexicanos, ello se 
debe a la relación de supra-subordinación entre los representantes del Estado y los gobernados en virtud de los cuales los primeros afectan la esfera jurídica de los segundos; esto es, el Estado al desplegar su actividad afecta los bienes y derechos de los gobernados cuando se impone en el ejercicio de su poder. Así, este Estado moderno interviene de forma reiterada, intensa y generalmente contundente en muchas áreas de la vida de los gobernados afectando sus derechos, incluso aquellos que el subordinado tiene en la más alta estima, aquellos que son básicos para su subsistencia, porque el Estado (en ejercicio de los diferentes poderes de la Unión) legisla, dicta y emite actos que trascienden la esfera jurídica de cada uno, o que carecen de respaldo legal o del respaldo legal adecuado o suficiente.

El segundo principio que abordaremos, establecido en un criterio jurisprudencial por nuestro máximo tribunal, criterio que rige la vida pública de México, local o federal, en su aspecto de cumplimiento constitucional de las contribuciones para ser consideradas válidas, es el de proporcionalidad y equidad. La Suprema Corte de Justicia de la Nación ha establecido criterio que define como requisitos mínimos indispensables con los que debe cumplir el legislador en el momento de la creación de la norma jurídica, el de proporcionalidad, el cual alude a la necesidad de que la actuación de los órganos legislativos, federales o locales, sea idónea para obtener los fines que se persiguen, que en el momento de crear e interpretar las leyes deben fijar sus alcances de forma ponderada en donde se tomen en cuenta determinados criterios, tales como:

1. Perseguir una finalidad constitucionalmente legítima.

2. Ser adecuada, idónea, apta y susceptible de alcanzar el fin perseguido.

3. Ser necesaria, es decir, suficiente para lograr dicha finalidad, de tal forma que no implique una carga desmedida, excesiva o injustificada para el gobernado, y

4. Estar justificada en razones constitucionales. 
Lo anterior quedo definido en sesión privada del 15 de enero de 2007, en donde el Pleno de la SCJN aprobó la Tesis Jurisprudencial Núm. 130/2007, misma que lleva por rubro "Garantías Individuales. El desarrollo de sus límites y la regulación de sus posibles conflictos por parte del legislador debe respetar los principios de razonabilidad y proporcionalidad jurídica”.

Dicha tesis establece que el cumplimiento de los principios de razonabilidad y proporcionalidad implica que al fijar el alcance de una garantía individual por parte del legislador se deben tener en cuenta determinados límites, ya que de acuerdo con el principio de legalidad el legislador no puede actuar en exceso de poder ni arbitrariamente en perjuicio de los gobernados.

De ahí que sea válido afirmar que debe existir una interpretación conforme a la Constitución y desde la Constitución, es decir, los valores fundamentales ahí contenidos deben irradiar a todos los ordenamientos jurídicos.

Un verdadero Estado constitucional no sólo se sostiene en el estricto respeto al derecho, sino en el contenido de un orden jurídico conforme a la razón y orientado por el valor de la justicia. Así, en el principio de racionalidad del derecho se implican las prohibiciones de arbitrariedad y de exceso en el ejercicio de poder público, íntimamente relacionadas con el principio de proporcionalidad.

$\mathrm{Al}$ expedir una norma el legislador realiza en su exposición de motivos un análisis ponderado de las razones que lo han llevado a legislar sobre una determinada materia o cambiar la normativa ya existente sobre la misma. La fundamentación y motivación de la expedición de una ley debe obligar al legislador a argumentar cuáles son los elementos de hecho y de derecho de la creación de una norma. 
Para la Suprema Corte de Justicia de la Nación, la seguridad jurídica es la certeza que debe tener el gobernado de que su persona, su familia, sus posesiones o sus derechos, los cuales serán respetados por la autoridad, pero si ésta debe producir una afectación en ellos, deberá ajustarse a los procedimientos previamente establecidos en la Constitución Política de los Estados Unidos Mexicanos y las leyes secundarias.

Nuestro máximo tribunal, define a las garantías de seguridad jurídica como aquellos derechos subjetivos públicos a favor de los gobernados, que pueden ser oponibles a los órganos estatales, a fin de exigirles que se sujeten a un conjunto de requisitos previos a la comisión de actos que pudieran afectar la esfera jurídica de los individuos, para que éstos no caigan en la indefensión o la incertidumbre jurídica, lo que hace posible la pervivencia de condiciones de igualdad y libertad para todos los sujetos de derechos y obligaciones. El artículo 14 Constitucional, establece la garantía de audiencia, como garantía de seguridad jurídica para los gobernados, y cuyo respeto es obligatorio para todas las autoridades, tanto legislativas, ejecutivas y judiciales.

Toda norma tributaria perteneciente al orden jurídico nacional y responde a la convicción general de emanar de la Constitución General de la República como norma fundamental para ser considerada válida; sus principios han sido estudiados y definidos en criterios jurisprudenciales por la Suprema Corte de Justicia de la Nación.

Los principios tributarios en México, para ser considerados válidos, trascendentales y obligatorios, deben forzosamente emanar de alguno de los preceptos constitucionales; de lo contrario serían de fácil desobediencia y por ende de aplicación innecesaria. Los principios de legalidad, de proporcionalidad y razonabilidad, de equidad, el respetar la garantía de seguridad jurídica y de audiencia es obligatoria para todas las autorida- 
des, tanto legislativas, ejecutivas y judiciales, en el ámbito local o federal.

Algunos juristas han coincidido en que es ilegal e inconstitucional la manera en que se determinan los precios del combustible y consecuentemente sus impuestos, por violar algunos de los principios tributarios, postulado en el que coincido por las siguientes razones:

b) Viola el principio de doble imposición

El principio de doble tributación establece que ninguna base podrá estar doblemente gravada, en el caso de las gasolinas pagamos tres IEPS e IVA sobre dos de ellos. En este punto tomo como bibliografía principal dos textos. El primero titulado "El problema de la Concurrencia de Impuestos en la República Mexicana”; y, el segundo el Marco Jurídico y Reglamentario del Sistema Nacional de Coordinación Fiscal.

La competencia y distribución de los impuestos que le corresponden a cada nivel de gobierno no está delimitada de manera detallada en la Constitución de la República, su sistema es complejo. Sin embargo, se entienden reservadas de la Federación la imposición de cargas relativas a aquellas actividades señaladas en el artículo 73, fracción XXIX, pero que puede establecer todo tipo de contribuciones si tiene por objeto cubrir su Presupuesto, a saber:

Artículo 73. El Congreso tiene facultad:

VII. Para imponer las contribuciones necesarias a cubrir el Presupuesto.

XXIX. Para establecer contribuciones:

1. Sobre el comercio exterior;

2. Sobre el aprovechamiento y explotación de los recursos naturales comprendidos en los párrafos $4^{\circ} \mathrm{y}$ $5^{\text {o }}$ del artículo 27;

3. Sobre instituciones de crédito y sociedades de seguros; 
4. Sobre servicios públicos concesionados o explotados directamente por la Federación; y

5. Especiales sobre:
a) Energía eléctrica;
b) Producción y consumo de tabacos labrados;
c) Gasolina y otros productos derivados del petróleo;
d) Cerillos y fósforos;
e) Aguamiel y productos de su fermentación; y
f) Explotación forestal.
g) Producción y consumo de cerveza.

Las entidades federativas participarán en el rendimiento de estas contribuciones especiales, en la proporción que la ley secundaria federal determine. Las legislaturas locales fijarán el porcentaje correspondiente a los Municipios, en sus ingresos por concepto del impuesto sobre energía eléctrica.

De acuerdo a Miguel Ortiz Ruiz el Convenio de Adhesión al Sistema Nacional de Coordinación Fiscal es un instrumento jurídico administrativo que formaliza la incorporación de una entidad federativa al Sistema. Si bien su composición es uniforme para todas las entidades, pueden adicionar acuerdos específicos llamados anexos. Como se señalaba, su finalidad es operativizar los acuerdos entre gobierno federal y entidades federativas para evitar la sobreposición de gravámenes fiscales y coadyuvar a las haciendas públicas.

$\mathrm{Al}$ respecto, es necesario traer a colación la Tesis I.15º $\mathrm{A} .173 \mathrm{~A}$ del Décimo Quinto Tribunal Colegiado en Materia Administrativa del Primer Circuito, correspondiente a la Novena Época publicada en la página 2007 correspondiente al Tomo XXXIV de Julio de 2011, del Seminario Judicial de la Federación y su Gaceta: 


\section{DOBLE O MÚLTIPLE TRIBUTACIÓN. SE ACTUALIZA ANTE LA IDENTIDAD DE OBJETO DE DOS O MÁS CONTRIBUCIONES.}

El tributo es una prestación patrimonial de carácter coactivo, a título definitivo, que de manera unilateral fija el Estado a cargo de las personas que realizan determinada conducta lícita, definida legalmente mediante una hipótesis jurídica o de hecho que es reflejo de su capacidad económica, y cuyo destino es financiar el gasto público. Por consiguiente, el tributo tiene como fuente una manifestación económica o de riqueza que puede tener diferentes representaciones, tales como la propiedad o tenencia de bienes o valores, el trabajo, la producción, la distribución o comercialización y el consumo de bienes y servicios, por lo que el objeto de la imposición se traduce en el relativo ingreso, el rendimiento o la utilidad esperada, que son gravados por el legislador. Sobre tales premisas, es inconcuso que la doble o múltiple tributación recae indefectiblemente en el objeto de la contribución, en tanto revela que el mismo ingreso, rendimiento o utilidad esperada, derivados de una misma representación de capacidad económica está afectado por varios tributos a la vez.

DÉCIMO QUINTO TRIBUNAL COLEGIADO EN MATERIA ADMINISTRATIVA DEL PRIMER CIRCUITO.

Amparo en revisión 336/2010. Joe Hamui Shabot y otros. 29 de Septiembre de 2010. Unanimidad de votos. Ponente: Armando Cortés Galván. Secretario: Roberto Fraga Jiménez.

La doble tributación es un fenómeno por completo negativo para nuestro régimen fiscal, obliga a los ciudadanos a contribuir en exceso, lo que merma el ingreso del contribuyente. Esto ocurre con el combustible, como hemos visto, al gravar con tasas distintas triplemente con IEPS la misma base, merma el ingreso del contribuyente. En este caso, la doble tributación como simple acumulación de impuestos no responde a gravar actividades productivas el contribuyente, si no acumular ingresos 
fiscales por el simple cobro de impuesto sobre impuesto, disminuyendo el patrimonio del contribuyente; de esta manera se rompe también el principio de proporcionalidad tributaria establecido en la fracción IV del artículo 31 de la constitución Federal.

C) El principio de proporcionalidad tributaria

Nuestro Alto Tribunal, ha establecido criterio que define como requisitos mínimos indispensables con los que debe cumplir el legislador en el momento de la creación de la norma jurídica, el de proporcionalidad, el cual alude a la necesidad de que la actuación de los órganos legislativos sea idónea para obtener los fines que se persiguen, que en el momento de crear e interpretar las leyes deben fijar sus alcances de forma ponderada en donde se tomen en cuenta determinados criterios, tales como:

1. Perseguir una finalidad constitucionalmente legítima.

2. Ser adecuada, idónea, apta y susceptible de alcanzar el fin perseguido.

3. Ser necesaria, es decir, suficiente para lograr dicha finalidad, de tal forma que no implique una carga desmedida, excesiva o injustificada para el gobernado, $\mathrm{y}$

4. Estar justificada en razones constitucionales.

Lo anterior quedo definido en sesión privada del 15 de enero de 2007, en donde el Pleno de la SCJN aprobó la Tesis Jurisprudencial Núm. 130/2007, misma que lleva por rubro "Garantías Individuales. El desarrollo de sus límites y la regulación de sus posibles conflictos por parte del legislador debe respetar los principios de razonabilidad y proporcionalidad jurídica”

De lo anterior se colige que el Estado de Derecho no únicamente implica el cumplimiento de la norma, sino en el contenido de un orden jurídico conforme a la razón y orientado por el valor de la justicia. El orden jurídico se sustenta en los principios de proporcionalidad y razonabilidad. 
El Pleno de la Suprema Corte de Justicia de la Nación ha sostenido que el principio de proporcionalidad tributaria establecido en el artículo 31, fracción IV de la Constitución, mediante Jurisprudencia de Pleno, Séptima Época, Apéndice de 1995, Tomo I, Parte SCJN, Página 256, en los siguientes términos:

PROPORCIONALIDAD Y EQUIDAD TRIBUTARIAS ESTABLECIDAS EN EL ARTÍCULO 31, FRACCION IV, CONSTITUCIONAL.

El artículo 31, fracción IV, de la Constitución establece los principios de proporcionalidad y equidad en los tributos. La proporcionalidad radica, medularmente, en que los sujetos pasivos deben contribuir a los gastos públicos en función de su respectiva capacidad económica, debiendo aportar una parte justa y adecuada de sus ingresos, utilidades o rendimientos. Conforme a este principio, los gravámenes deben fijarse de acuerdo con la capacidad económica de cada sujeto pasivo, de manera que las personas que obtengan ingresos elevados tributen en forma cualitativa superior a los de medianos y reducidos recursos. El cumplimiento de este principio se realiza a través de tarifas progresivas, pues mediante ellas se consigue que cubran un impuesto en monto superior los contribuyentes de más elevados recursos. Expresado en otros términos, la proporcionalidad se encuentra vinculada con la capacidad económica de los contribuyentes que debe ser gravada diferencialmente, conforme a tarifas progresivas, para que en cada caso el impacto sea distinto, no sólo en cantidad, sino en lo tocante al mayor o menor sacrificio reflejado cualitativamente en la disminución patrimonial que proceda, y que debe encontrarse en proporción a los ingresos obtenidos. El principio de equidad radica medularmente en la igualdad ante la misma ley tributaria de todos los sujetos pasivos de un mismo tributo, los que en tales condiciones deben recibir un tratamiento idéntico en lo concerniente a hipótesis de causación, acumulación de ingresos gravables, deduccio- 
nes permitidas, plazos de pago, etc., debiendo únicamente variar las tarifas tributarias aplicables, de acuerdo con la capacidad económica de cada contribuyente, para respetar el principio de proporcionalidad antes mencionado. La equidad tributaria significa, en consecuencia, que los contribuyentes de un mismo impuesto deben guardar una situación de igualdad frente a la norma jurídica que lo establece y regula.

Como se observa, en el caso de los impuestos a los combustibles no son proporcionales, el legislador no diferencia la capacidad económica de los contribuyentes en función de los ingresos que obtienen. Lo mismo paga un ciudadano de escasos ingresos que una persona moral el sector de grandes contribuyentes. No existe tampoco en el caso de los combustibles la imposición de tarifas progresivas, mucho menos es gravada diferencialmente.

En el caso concreto, al establecer el legislador y la autoridad fiscal cargas impositivas iguales a todos los contribuyentes, viola el principio de proporcionalidad establecido por la Suprema Corte de Justicia de la Nación y el de la fracción IV del artículo 31 de la Constitución.

d) Principio de certeza o certidumbre tributaria

El contribuyente o ciudadano desconoce cuánto cuesta, cuál es la base y la manera en que se calcula el producto y por ende los impuestos del combustible. Tampoco tenemos certeza o certidumbre del precio de hoy, mucho menos en unos meses cuando pronostican gasolinazos diarios.

Adicionalmente, viola también el principio de certeza tributaria en tanto que el ciudadano desconoce a ciencia cierta uno de los elementos del tributo: el Sujeto; de la lectura del Artículo 2 A de la Ley del IEPS, lo mismo puede interpretarse que es Pemex o los distribuidores, pero en los hechos somos los ciudadanos quienes cargamos con el costo de este impuesto. 
De conformidad a la doctrina, todo tributo debe poseer fijeza en sus elementos constitutivos, ya que de otra manera se da paso al abuso y a la arbitrariedad de las autoridades encargadas de la recaudación, las que a su capricho puedan llegar a fijar las cuotas impositivas, fechas de pago, obligaciones a satisfacer. ${ }^{5}$

En tales condiciones, la primera obligación de la ley fiscal está constituida por el deber ineludible de establecer con certeza los elementos constitutivos de cada tributo para, en esa forma, actuar como barrera eficaz contra cualquier posible desvío de poder. El principio de certidumbre confiere al ciudadano común y corriente un poderoso medio de defensa frente a los excesos de la Hacienda Pública, al permitirle conocer correctamente y de antemano hasta dónde llegan sus obligaciones tributarias y cuál es el límite de la potestad recaudatoria.

En efecto, avalar la entrada en vigor de la reforma es contrario a la garantía de seguridad jurídica, pilar fundamental del sistema jurídico mexicano, implicaría estar creando un poder de facto para las autoridades fiscales que podrán realizar de manera indiscriminada actos para determinar los precios de los productos y las cargas fiscales a los contribuyentes, dejando al ciudadano en estado de indefensión, ya que en el contenido de la norma no se sabe a ciencia cierta el costo del combustible y de los tributos, en consecuencia de ello los contribuyentes no sabrán a qué atenerse con la entrada en vigor de esta obligación.

A lo anterior resulta aplicable la jurisprudencia 1a./J. 139/2012 (10a.) emitida por la Primera Sala de la Suprema Corte de Justicia de la Nación, localizable en el Semanario Judicial de la Federación y su Gaceta Libro XVI, Enero de 2013, Tomo 1, página 437, la cual establece lo siguiente:

\footnotetext{
${ }^{5}$ Arrioja Vizcaíno, Adolfo, Derecho Fiscal. México, Editorial Themis, 2003, p. 576.
} 
SEGURIDAD JURÍDICA EN MATERIA TRIBUTARIA. EN QUÉ CONSISTE.

La Primera Sala de la Suprema Corte de Justicia de la Nación ha sostenido que el principio de seguridad jurídica consagrado en la Constitución General de la República, es la base sobre la cual descansa el sistema jurídico mexicano, de manera tal que lo que tutela es que el gobernado jamás se encuentre en una situación de incertidumbre jurídica y, por tanto, en estado de indefensión. En ese sentido, el contenido esencial de dicho principio radica en "saber a qué atenerse" respecto de la regulación normativa prevista en la ley y a la actuación de la autoridad. Así, en materia tributaria debe destacarse el relevante papel que se concede a la ley (tanto en su concepción de voluntad general, como de razón ordenadora) como instrumento garantizador de un trato igual (objetivo) de todos ante la ley, frente a las arbitrariedades y abusos de la autoridad, lo que equivale a afirmar, desde un punto de vista positivo, la importancia de la ley como vehículo generador de certeza, y desde un punto de vista negativo, el papel de la ley como mecanismo de defensa frente a las posibles arbitrariedades de los órganos del Estado. De esta forma, las manifestaciones concretas del principio de seguridad jurídica en materia tributaria, se pueden compendiar en la certeza en el derecho y la interdicción de la arbitrariedad o prohibición del exceso; la primera, a su vez, en la estabilidad del ordenamiento normativo, suficiente desarrollo y la certidumbre sobre los remedios jurídicos a disposición del contribuyente, en caso de no cumplirse con las previsiones del ordenamiento; y, la segunda, principal, más no exclusivamente, a través de los principios de proporcionalidad y jerarquía normativa, por lo que la existencia de un ordenamiento tributario, partícipe de las características de todo ordenamiento jurídico, es producto de la juridificación del fenómeno tributario y su conversión en una realidad normada, y tal ordenamiento público constituirá un sistema de seguridad jurídica formal o de "seguridad a través del Derecho”. 
Del criterio jurisprudencial citado anteriormente se desprende que la garantía de seguridad jurídica es la base sobre la cual descansa el sistema jurídico mexicano, lo que tutela esta garantía es que el gobernado jamás se encuentre en una situación de incertidumbre jurídica y por tanto en estado de indefensión. El contenido esencial de dicho principio es el que el gobernado sepa a qué atenerse respecto de la regulación normativa prevista en la ley y a la actuación de la autoridad.

El principio de seguridad jurídica cobra especial relevancia en materia tributaria ya que se le concede a la ley un relevante papel como mecanismo de defensa frente a las posibles arbitrariedades de los órganos del Estado, sin embargo en la norma que establece los precios del combustible el legislador creó normas que dotan a las autoridades fiscales de imperio para realizar actos de manera arbitraria ya que va en contra de lo estipulado en el artículo 16 de la Constitución Política de los Estados Unidos Mexicanos.

Resulta aplicable la jurisprudencia 2a./J. 144/2006 emitida por la Segunda Sala de la Suprema Corte de Justicia de la Nación, localizable en el Semanario Judicial de la Federación y su Gaceta Tomo XXIV, Octubre de 2006, página 351, misma que establece lo siguiente:

\section{GARANTÍA DE SEGURIDAD JURÍDICA. SUS ALCANCES.}

La garantía de seguridad jurídica prevista en el artículo 16 de la Constitución Política de los Estados Unidos Mexicanos, no debe entenderse en el sentido de que la ley ha de señalar de manera especial y precisa un procedimiento para regular cada una de las relaciones que se entablen entre las autoridades y los particulares, sino que debe contener los elementos mínimos para hacer valer el derecho del gobernado y para que, sobre este aspecto, la autoridad no incurra en arbitrariedades, lo que explica que existen trámites o relaciones que por su simplicidad o sencillez, no requieren de que la ley pormenorice un procedimiento detallado para ejercer el derecho correlativo. Lo anterior corrobora que 
es innecesario que en todos los supuestos de la ley se deba detallar minuciosamente el procedimiento, cuando éste se encuentra definido de manera sencilla para evidenciar la forma en que debe hacerse valer el derecho por el particular, así como las facultades y obligaciones que le corresponden a la autoridad.

Atento al criterio antes citado, la garantía de seguridad jurídica no debe entenderse en el sentido de que la ley debe de precisar un procedimiento de regulación para cada una de las relaciones que se den entre los órganos del Estado y los gobernados, sino que debe de contener los elementos mínimos para que el gobernado pueda hacer valer sus derechos y para que la autoridad no incurra en arbitrariedades.

e) Principio de legalidad y de constitucionalidad

Como lo señala Roberto Islas Montes en el Anuario de Derecho Constitucional Latinamericano:

El principio de legalidad es un principio fundamental. Generalmente es reconocido por los ordenamientos supremos como la Constitución Política de los Estados Unidos Mexicanos, ello se debe a la relación de supra-subordinación entre los representantes del Estado y los gobernados en virtud de los cuales los primeros afectan la esfera jurídica de los segundos; esto es, el Estado al desplegar su actividad afecta los bienes y derechos de los gobernados cuando se impone en el ejercicio de su poder. Así, este Estado moderno interviene de forma reiterada, intensa y generalmente contundente en muchas áreas de la vida de los gobernados afectando sus derechos, incluso aquellos que el subordinado tiene en la más alta estima, aquellos que son básicos para su subsistencia, porque el Estado (en ejercicio de los diferentes poderes de la Unión) legisla, dicta y emite actos que trascienden la esfera jurídica de cada uno, o que carecen de respaldo legal o del respaldo legal adecuado o suficiente. 
En contravención al principio de legalidad y constitucionalidad, en el caso de la determinación de precios al combustible y por ende de sus tributos, quien establece los precios máximos de gasolina es la Comisión Reguladora de Energía con la opinión de la Comisión Federal de Competencia Económica, facultad que se estableció en el artículo Décimo Segundo Transitorio de la Ley de Ingresos de la Federación para 2017; esa facultad es exclusiva del Congreso de la Unión según el artículo 73 fracción XXIX de la Constitución Política de los Estados Unidos Mexicanos; por lo tanto es violatorio del principio de legalidad tributaria y a todas luces una medida inconstitucional.

Transitorios de la Ley de Ingresos de la Federación para el Ejercicio Fiscal de 2017

Décimo Segundo. Durante 2017 y 2018 los precios al público de las gasolinas y el diésel se determinarán de conformidad con lo siguiente: I. La Comisión Reguladora de Energía, tomando en cuenta la opinión que emita la Comisión Federal de Competencia Económica, emitirá los acuerdos o el cronograma de flexibilización para que durante los años de 2017 y 2018 los precios al público se determinen bajo condiciones de mercado. Los acuerdos o el cronograma se establecerán por regiones del país. La Comisión Reguladora de Energía podrá modificar dichos acuerdos o cronograma, con base en la evolución de las condiciones de mercado y el desarrollo de la infraestructura de suministro en el país, entre otros factores. La Comisión Reguladora de Energía deberá publicar en el Diario Oficial de la Federación los acuerdos o el cronograma actualizados. Las modificaciones únicamente podrán llevarse a cabo para adelantar el momento a partir del cual los precios al público se determinarán bajo condiciones de mercado.

II. a III. ... 
Para visualizar lo que se entiende por principio de legalidad, de reserva de ley y de supremacía de ley, se debe iniciar analizando lo que se considera un principio de derecho, entendiéndolo como todas aquellas pautas que establecen los lineamientos principales de un ordenamiento jurídico, que otorgan un sentido determinado al derecho positivo, y puede decirse que constituyen su fuente de validez; motivo por el que todo problema jurídico que no encuentre una respuesta satisfactoria en el derecho positivo y la jurisprudencia aplicable, puede hallar solución en los principios que modelen a cada ordenamiento jurídico concreto.

Por su parte, el Diccionario de la Real Academia Española de la Lengua establece que el término "principio" significa, entre otros, "punto que se considera como primero en una extensión o cosa”, "base, origen, razón fundamental sobre la cual se procede discurriendo en cualquier materia”, "causa, origen de algo", "cualquiera de las primeras proposiciones o verdades fundamentales por donde se empiezan a estudiar las ciencias o las artes".

Para algunos juristas, el principio de reserva de ley en materia tributaria es relativo, toda vez que aplica solamente a los aspectos esenciales del tributo, empero un gran sector de la doctrina mexicana considera que en materia tributaria hay una reserva absoluta de ley; ello toda vez que los juristas que sostienen dicha postura consideran que la reserva absoluta es aquella que cubre una cierta parte del ámbito tributario exigiendo que las normas que la regulen tengan el rango de Ley.

Partiendo de lo anterior, el origen según los doctrinarios del principio de reserva de ley, surge del principio de legalidad, protegido y reconocido en nuestra Carta Magna, así, el principio de legalidad tributaria rige dos esferas (i) la esfera administrativa, donde se aplica el principio de legalidad administrativa (o también llamado preeminencia de la ley) y (ii) la esfera normativa, donde tiene aplicación el principio de reserva de ley. 
En ese orden, el principio de reserva de ley tiene como función principal limitar la potestad tributaria normativa del Estado, al acotar un determinado ámbito de la realidad social en exclusiva a la ley, es decir, que determinadas materias deberán ser reguladas exclusivamente por la ley y no por reglas o reglamentos generales que no siguen el proceso legislativo como tal.

Trasladando dicho principio al ámbito tributario, se traduciría en que todos o algunos elementos referentes a la materia tributaria deben ser regulados por Ley.

El principio de reserva de ley en materia tributaria tiene como objetivo que las contribuciones que debe sufragar el ciudadano no sean mayores que la de su libertad individual, ni patrimonial; pues, debe garantizarse la seguridad jurídica del ciudadano frente al sistema tributario.

En el derecho mexicano el principio de Reserva de Ley en materia tributaria se encuentra establecido en el artículo 31 fracción IV de la Constitución Mexicana, que señala: Son obligaciones de los mexicanos: ... IV.- Contribuir para los gastos públicos, así de la Federación, como del Distrito Federal o del Estado y Municipio en que residan, de la manera proporcional y equitativa que dispongan las leyes. Esta faz de la reserva de ley es conocida como su aspecto positivo.

En este sentido, el Poder Judicial Federal ha sostenido lo siguiente:

Tesis: P. XLII/2006

Semanario Judicial de la Federación y su Gaceta

Novena Época

175059

Pleno

Tesis Aislada(Constitucional, Administrativa)

LEGALIDAD TRIBUTARIA. EL PRINCIPIO DE RESERVA DE LEY ES DE CARÁCTER RELATIVO Y SÓLO ES APLICABLE 


\section{TRATÁNDOSE DE LOS ELEMENTOS QUE DEFINEN A LA CUANTÍA DE LA CONTRIBUCIÓN.}

El Tribunal en Pleno de la Suprema Corte de Justicia de la Nación ha sostenido que en materia de legalidad tributaria la reserva de ley es de carácter relativo, toda vez que dicha materia no debe ser regulada en su totalidad por una ley formal y materialmente legislativa, sino que es suficiente que los elementos esenciales de la contribución se describan en ella, para que puedan ser desarrollados en otros ordenamientos de menor jerarquía, ya que la presencia del acto normativo primario marca un límite de contenido para las normas secundarias posteriores, las cuales nunca podrán contravenir la norma primaria, además de que tal remisión debe constituir un complemento de la regulación legal que sea indispensable por motivos técnicos o para el debido cumplimiento de la finalidad recaudatoria. En congruencia con tal criterio, se concluye que el principio tributario de reserva de ley es de carácter relativo y aplica únicamente tratándose de los elementos cuantitativos del tributo, como son la tasa o la base, porque en muchas ocasiones, para cifrar el hecho imponible es indispensable realizar operaciones o acudir a aspectos técnicos, lo que no sucede en relación con los elementos cualitativos de las contribuciones, como son los sujetos y el objeto, los cuales no pueden ser desarrollados en un reglamento, sino que deben preverse exclusivamente en una ley.

Tesis: P. CXLVIII/97

Semanario Judicial de la Federación y su Gaceta

Novena Época

Pleno

Tesis Aislada(Administrativa, Constitucional)

LEGALIDAD TRIBUTARIA. ALCANCE DEL PRINCIPIO DE RESERVA DE LEY. 
Conforme con dicho principio, es necesaria una ley formal para el establecimiento de los tributos, lo que satisface la exigencia de que sean los propios gobernados, a través de sus representantes, los que determinen las cargas fiscales que deben soportar, así como que el contribuyente pueda conocer con suficiente precisión el alcance de sus obligaciones fiscales, de manera que no quede margen a la arbitrariedad. Para determinar el alcance o profundidad del principio de legalidad, es útil acudir al de la reserva de ley, que guarda estrecha semejanza y mantiene una estrecha vinculación con aquél.

Los elementos sustanciales de los impuestos deben ser contemplados en normas tributarias, y para efectos de lo anterior, lo que integra detalladamente el de los combustibles es una cuestión sustancial, pues de lo contrario el contribuyente gobernado carece de la certeza de lo que debe ser considerado como costo del combustible y sus tributos.

Como hemos sostenido, la Comisión Reguladora de Energía determina ahora los precios de los combustibles y sus tributos, en contravención al principio constitucional establecido en el artículo 73 fracción XXIX, al respecto, resulta aplicable la tesis número P. XXI/2003 sustentada por el Pleno de la Suprema Corte de Justicia de la Nación, bajo el texto y rubro siguientes:

Época: Novena Época

Registro: 182710

Instancia: Pleno

Tipo de Tesis: Aislada

Fuente: Semanario Judicial de la Federación y su Gaceta

Tomo XVIII, Diciembre de 2003

Materia(s): Constitucional

Tesis: P. XXI/2003

Página: 9 


\section{CLÁUSULAS HABILITANTES. CONSTITUYEN ACTOS FOR- MALMENTE LEGISLATIVOS.}

En los últimos años, el Estado ha experimentado un gran desarrollo en sus actividades administrativas, lo que ha provocado transformaciones en su estructura y funcionamiento, y ha sido necesario dotar a funcionarios ajenos al Poder Legislativo de atribuciones de naturaleza normativa para que aquél enfrente eficazmente situaciones dinámicas y altamente especializadas. Esta situación ha generado el establecimiento de mecanismos reguladores denominados “cláusulas habilitantes", que constituyen actos formalmente legislativos a través de los cuales el legislador habilita a un órgano del Estado, principalmente de la administración pública, para regular una materia concreta y específica, precisándole bases y parámetros generales y que encuentran su justificación en el hecho de que el Estado no es un fenómeno estático, pues su actividad no depende exclusivamente de la legislación para enfrentar los problemas que se presentan, ya que la entidad pública, al estar cerca de situaciones dinámicas y fluctuantes que deben ser reguladas, adquiere información y experiencia que debe aprovechar para afrontar las disyuntivas con agilidad y rapidez. Además, la adopción de esas cláusulas tiene por efecto esencial un fenómeno de ampliación de las atribuciones conferidas a la administración y demás órganos del Estado, las cuales le permiten actuar expeditamente dentro de un marco definido de acción, susceptible de control a través del principio de legalidad; en la inteligencia de que el establecimiento de dicha habilitación normativa debe realizarse en atención a un equilibrio en el cual se considere el riesgo de establecer disposiciones que podrían propiciar la arbitrariedad, como generar situaciones donde sea imposible ejercer el control estatal por falta de regulación adecuada, lo que podría ocurrir de exigirse que ciertos aspectos dinámicos se normen a través de una ley. Amparo en revisión 199/2002. Moisés Saba Masri. 9 de septiembre de 2003. Mayoría de seis votos. Ausentes: Guillermo I. Ortiz Mayagoitia y 
Humberto Román Palacios. Disidentes: Juventino V. Castro y Castro, José de Jesús Gudiño Pelayo y Juan N. Silva Meza. Ponente: José Vicente Aguinaco Alemán. Secretario: Emmanuel G. Rosales Guerrero.

El Tribunal Pleno, en su sesión privada celebrada hoy trece de noviembre en curso, aprobó, con el número XXI/2003, la tesis aislada que antecede; y determinó que la votación no es idónea para integrar tesis jurisprudenciales. México, Distrito Federal, a trece de noviembre de dos mil tres.

De lo anterior se desprende sin duda que las normas señaladas son inconstitucionales, en virtud de infringir el principio de subordinación jerárquica previsto en el artículo 89, fracción I de la Constitución Federal.

Esto se afirma porque basta con analizar el artículo Decimosegundo transitorio de la Ley de Ingresos de la Federación 2017, el cual en la parte que interesa dice lo siguiente:

Décimo Segundo. Durante 2017 y 2018 los precios al público de las gasolinas y el diésel se determinarán de conformidad con lo siguiente:

I. La Comisión Reguladora de Energía, tomando en cuenta la opinión que emita la Comisión Federal de Competencia Económica, emitirá los acuerdos o el cronograma de flexibilización para que durante los años de 2017 y 2018 los precios al público se determinen bajo condiciones de mercado. Los acuerdos o el cronograma se establecerán por regiones del país. La Comisión Reguladora de Energía podrá modificar dichos acuerdos o cronograma, con base en la evolución de las condiciones de mercado y el desarrollo de la infraestructura de suministro en el país, entre otros factores. La Comisión Reguladora de Energía deberá publicar en el Diario Oficial de la Federación los acuerdos o el cronograma actualizados. Las modificaciones únicamente podrán llevarse a cabo para adelantar el momento a partir del cual los precios al público se determinarán bajo condiciones de mercado. 
Como hemos afirmado, las disposiciones del artículo Decimosegundo Transitorio son inconstitucionales, porque su creación no obedece al establecimiento de bases y parámetros generales, no se establecieron dichas bases y parámetros para normar la facultad de la Comisión Reguladora de Energía, lo cual sin duda es motivo de inconstitucionalidad de dicho precepto. Es invasivo de la facultad exclusiva del Congreso de la Unión.

Lo anterior implica una violación al principio de subordinación jerárquica previsto en el artículo 89, fracción I de la Constitución Federal.

\section{V. ¿QUÉ RESTA POR HACER?}

La Reforma Energética representaba la oportunidad de mayores condiciones de competencia, los consumidores podríamos decidir que combustible adquirir en función de calidad y precio. Si los privados, extranjeros o nacionales, desean competir por el mercado de Pemex que lo hagan en condiciones favorables para los ciudadanos. Lo ilógico es que el Gobierno Federal haya promovido un incremento de precios de combustibles una año antes de la apertura del mercado a competidores internacionales, haciendo más atractivo el negocio a capitales externos y garantizando el retorno de la inversión en menor tiempo: ganan los capitales privados en detrimento de la economía de las familias.

Ante esta decisión, es claro que la apuesta del Gobierno Federal en turno fue al simple olvido, al cese de las marchas y manifestaciones sociales por el simple transcurso del tiempo.

En el caso de la gasolina solicitar decretar la inconstitucionalidad de la flexibilización de los combustibles es correcto, el Amparo es un medio de defensa al que todos tenemos derecho, aunque los tiempos para interpo- 
ner un medio de defensa constitucional han transcurrido, sabemos que el momento de hacer valer ese derecho puede ocurrir contra el primer acto de autoridad; pero es un camino largo, pesado y del cual ya hemos vivido múltiplesexperiencias. Podemos tomar esa opción, pero como ciudadanos tendríamos pocas posibilidades de materializarla: caminar por la ciudad con una suspensión provisional bajo el brazo para no pagar el IEPS o el IVA en las gasolinerías y que se respete una decisión judicial de esta naturaleza, parece prácticamente imposible.

Sin embargo, hay otra opción, los Acuerdos publicados para dar a conocer los montos de los estímulos fiscales aplicables a la enajenación de gasolinas.

Mientras que llevar a cabo todo un proceso contencioso que declare inconstitucional una norma o someterla a un proceso legislativo para reformarla debe darse, lo inmediato ahora es decretar el estímulo fiscal para el país y en especial para la región fronteriza que se encuentra en zona de competencia frente a los precios de los Estados Unidos. Su base legal está contenida en el artículo 31, fracción XXXIV de la Ley Orgánica de la Administración Pública Federal; Segundo, Quinto y transitorio Segundo del Decreto por el que se establecen estímulos fiscales en materia del impuesto especial sobre producción y servicios aplicables a los combustibles.

No bajar la guardia debe ser nuestra premisa ante cada acto de Gobierno que vulnere la integridad de nuestras familias. El país nos pertenece mientras seamos capaces de pelear por lo que creemos, nos opongamos con firmeza a decisiones injustas que ahondan nuestra dependencia y someten la voluntad soberana del pueblo. 


\section{FUENTES}

\section{BIBLIOGRAFIA}

Álvarez Alcalá, Alil, Lecciones de Derecho Fiscal, México, Editorial Oxford, 2009.

Carrasco Iriarte, Hugo, Diccionario de Derecho Fiscal, 3a ed., México, Oxford, 2013.

Chapoy Bonifaz, Dolores Beatriz, Derecho Fiscal, México, UNAM, 1991.

Ley del Impuesto al Valor Agregado

Ley del Impuesto Especial Sobre Producción y Servicios

Semanario Judicial de la Federación y su Gaceta.

Zambrano Torres, Alex R. Los Principios del Derecho Tributario. México: 2007. UNAM.

\section{HEMEROGRAFIA}

Contreras Borbón, Omar, "La falsa idea del subsidio", As, Asesores en Soluciones, México, en http://asesoresensoluciones.com/as/index.php/revista-electronica/enero-febrero-2017

\section{LEYES}

Constitución Política de los Estados Unidos Mexicanos.

Criterios Generales de Política Económica 2017 de la Secretaría de Hacienda en http://www.ppef.hacienda.gob.mx/work/models/PPEF2017/paquete/ politica_hacendaria/CGPE_2017.pdf

DOF. ACUERDO por el cual se dan a conocer los montos de los estímulos fiscales aplicables a la enajenación de gasolinas en la región fronteriza con los Estados Unidos de América, correspondientes al periodo que se especifica. 